\title{
Regenerative medicine repairs mice from top to toe
}

\section{Three separate studies in mice show normal function can be restored to hair, eye and heart cells.}

\author{
Leila Haghighat
}

18 April 2012

At the turn of the twentieth century, the promise of regenerating damaged tissue was so far-fetched that Thomas Hunt Morgan, despairing that his work on earthworms could ever be applied to humans, abandoned the field to study heredity instead. Though he won the Nobel Prize in 1933 for his work on the role of chromosomes in inheritance, if he lived today, the advances in regenerative medicine may have tempted him to reconsider.

Three studies published this week show that introducing new cells into mice can replace diseased cells — whether hair, eye or heart — and help to restore the normal function of those cells. These proof-of-principle studies now have researchers setting their sights on clinical trials to see if the procedures could work in humans.

"You can grow cells in a Petri dish, but that's not regenerative medicine," says Robin Ali, a geneticist at University College London, who led the eye study. "You have to think about the biology of repair in a living system."

\section{Sprouting hair}

In work published in Nature Communications, Japanese researchers grew different types of hair on nude mice, using stem cells from normal mice and balding humans to recreate the follicles from which hair normally emerges ${ }^{1}$. Takashi Tsuji, a regenerative-medicine specialist at Tokyo University of Science who led the study, says that the technique holds promise for treating male pattern baldness.

The team used a specialized nylon sheath to guide the hair through the skin layers, enabling it to erupt from the skin of the mice in $94 \%$ of all grafts. The hairs took between 2 and 5 weeks to emerge, and behaved as normal: they underwent normal

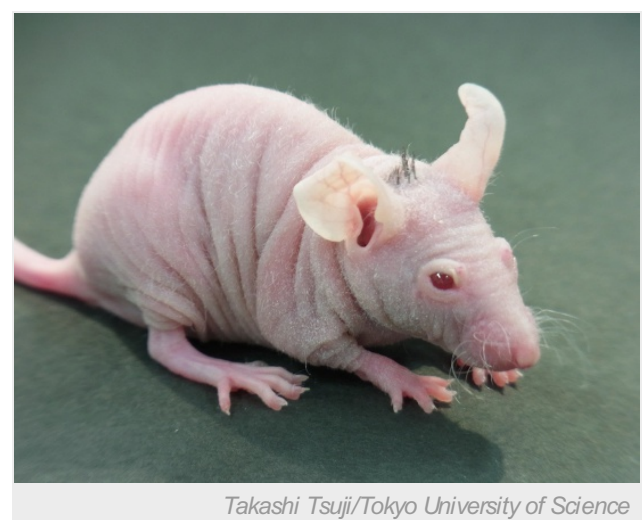

Transplanting bioengineered stem cells into nude mice enabled them to grow hair. growth cycles and established connections to the muscles and nerves underneath the skin. The hairs also lifted up from the skin in response to acetylcholine, a neurotransmitter known to cause hairs to stand on end.

Mayumi Ito, a dermatologist at New York University, says that this is the first report to reconstitute hair follicles using human cells. But for the technique to be effective, the researchers need to show that they can expand the number of hair follicles that they are able to grow.

\section{Seeing at night}

A second study using regenerative techniques helped to restore some vision to mice with congenital stationary night blindness, an inherited disease of the retina - the part of the eye that is sensitive to light ${ }^{2}$. The research, published in Nature, could potentially be used for treating macular degeneration, which causes damage to the retina.

Ali and his colleagues transplanted precursor rod cells, which have a role in night-time vision, into the retinas of mice lacking atransducin, a protein needed to see in dim light. Around 26,000 new rods were delivered into each eye, which normally contains 6 million rods. Only $10-15 \%$ of the rods integrated into the retina, but they still improved vision.

The researchers measured the effect of the transplant by placing the mice in front of a rotating grating of black and white lines and showing that they demonstrated more sensitivity to changing levels of contrast and spaces between the lines compared to blind mice that did not receive a transplant. The mice with transplanted rod cells also took less time to complete a water maze that used a visual cue to reveal the escape route.

Ali acknowledges that further animal studies are needed before beginning a clinical trial. He and his colleagues are now testing embryonic stem cells and other models of macular degeneration in which there is damage to the cones, another type of retinal cell. 


\section{Beating hearts}

But stem-cell transplants aren't always straightforward: if the cells fail to integrate into the desired tissue, they can form tumours instead. To avoid this problem, researchers have been trying to reprogram fully developed adult cells directly so that they form other cell types. Now, in a study published in Nature ${ }^{3}$, a team of researchers at the University of California, San Francisco (UCSF), has managed to achieve just that using cardiac fibroblasts.

Deepak Srivastava, director of the UCSF Gladstone Institute of Cardiovascular Disease, led a team in reprogramming cardiac fibroblasts into cardiomyocytes - the muscle cells of the heart that are permanently lost after a heart attack. The team used a retrovirus to deliver three transcription factors that induced the reprogramming in adult mice, and improved their cardiac function. This study follows on from work in 2003, when Srivastava and his colleagues discovered that a mutation in one of these transcription factors, GATA4, caused heart disease in several generations of a family under his care ${ }^{4}$. "What I do clinically, motivates me. Absolutely, every day," he says.

Robert Lanza, a regenerative-medicine specialist at Advanced Cell Technologies, a biotechnology firm headquartered in Santa Monica, California, reiterates that regenerative medicine has come a long way since Morgan's time, and is a field that holds much promise for the future. "These three papers are just the tip of the iceberg. By the time we grow old, doctors are going to look back and say, 'Can you believe people used to go bald, go blind or even have their leg cut off from vascular disease?' - and then the doctor will treat the problem with an injection of cells."

Nature I doi:10.1038/nature.2012.10472

\section{References}

1. Toyoshima, K. et al. Nature Commun. 3, 784 (2012).

2. Pearson, R. A. et al. Nature http://dx.doi.org/10.1038/nature10997 (2012).

3. Qian, L. et al. Nature http://dx.doi.org/10.1038/nature11044 (2012).

4. Garg, V. et al. Nature 424, 443-447 (2003). 